\title{
Effects of reviewing childbirth scenarios on choice of delivery type: a randomized controlled trial
}

\section{Doğum senaryolarını gözden geçirmenin doğum şekli seçimine etkileri: randomize kontrollü bir çalışma}

\author{
(1) Massome Rasoli1, (1) Seyed Mohammad Mirrezaie ${ }^{2}$, (1) Ensieh Fooladi3 ${ }^{3}$, (1) Robabeh Zarouj Hosseini ${ }^{4}$, \\ (1) Mahsa Fayaz 5 \\ 1Student Research Committee, School of Nursing and Midwifery, Shahroud University of Medical Sciences, Shahroud, Iran \\ 2 Shahroud University of Medical Sciences, Center for Health-Related Social and Behavioral Sciences Research, Shahroud, Iran \\ ${ }^{3}$ Mazandaran University of Medical Sciences, School of Nursing and Midwifery, Sari, Iran \\ ${ }^{4}$ Shahroud University of Medical Sciences, School of Nursing and Midwifery, Department of Medical Education, Shahroud, Iran \\ 5 Shahroud University of Medical Sciences, School of Public Health, Department of Epidemiology, Shahroud, Iran
}

\begin{abstract}
Objective: The incidence of cesarean section (CS) was estimated as about 48\% between 2000 and 2012 in Iran. This study was conducted to assess the effects of reviewing written childbirth scenarios on the selection of delivery method.

Materials and Methods: This randomized controlled trial was conducted in Shohada Women's Hospital in Behshahr, Mazandaran, Iran, from May to December 2015. A total of 223 women at 28 to 32 weeks of gestation were randomly allocated into three groups; the standard care (control), theory of planned behavior (TPB)-based education, and TPB education plus additional support via written childbirth scenarios (scenario). Participants were assessed at baseline (weeks 28-32) and intervention (week 37 of pregnancy) periods. Both intervention groups (TPB and scenario groups) participated in three learning sessions that were based on TPB, whereas the control group received routine care service.

Results: The frequencies of normal vaginal delivery (NVD) in the scenario, TPB, and control groups were $73.2 \%, 58.5 \%$, and $45.7 \%$, respectively $(\mathrm{p}=0.004)$. The results showed that the relative risks of CS decision in the scenario and TPB groups in comparison with the control group were both 0.87 and statistically significant ( $\mathrm{p}=0.018$ and $\mathrm{p}=0.013$, respectively). The relative risk of choosing CS after the removal of obligatory CS cases in the scenario group compared with the control was 0.85 .

Conclusion: Written childbirth scenarios that contain information on NVD and CS as additional support are effective educational tools for reducing CS rates.

Keywords: Cesarean section, theory of planned behavior, scenario, Iran

$\ddot{O} z$

Amaç: İran'da, 2000-2012 yılları arasında sezaryen doğum (SD) insidansının yaklaşık \%48 olduğu tahmin edilmektedir. Bu çalışmada, yazılı doğum senaryolarının gözden geçirilmesinin doğum yönteminin seçimine etkilerinin değerlendirilmesi amaçlanmıştır.

Gereç ve Yöntemler: Bu randomize kontrollü çalışma, Mayıs-Aralık 2015 tarihleri arasında, İran’in Mazandaran Eyaleti Behshahr kentindeki Shohada Kadın Hastanesi'nde yürütüldü. Gebeliğinin 28 ila 32. haftasında olan toplam 223 kadın rastgele üç gruba ayrıldı. Bunlar; standart bakım (kontrol), planlanmış davranış teorisi temelli eğitim (PDT) ve PDT artı yazılı doğum senaryolan ile ek destek (senaryo) idi. Katılımcılar başlangıç (28-32. hafta) ve müdahale (gebeliğin 37. haftası) dönemlerinde değerlendirildi. Her iki müdahale grubu da (PDT ve senaryo grupları) PDT temelli üç öğrenme oturumuna katılmış, kontrol grubu ise rutin bakım hizmeti almıștır.

Bulgular: Normal vajinal doğum (NVD) sıklı̆̆ senaryo, PDT ve kontrol gruplarında sirasıyla \%73,2, \%58,5 ve \%45,7 idi (p=0,004). Bulgular, senaryo ve PDT gruplarındaki SD kararının kontrol grubuyla karşılaştırıldığında göreceli risklerin her ikisinde 0,87 ve istatistiksel olarak anlamlı olduğunu göstermiştir (sırasıyla $\mathrm{p}=0,018$ ve $\mathrm{p}=0,013$ ). Senaryo grubundaki zorunlu SD olgularının çıkarılmasının ardından kontrole kıyasla SD seçiminde göreceli risk 0,85 idi. Sonuç: NVD ve ek destek olarak SD hakkında bilgi içeren yazılı doğum senaryoları, SD oranlarını azaltmak için etkili eğitim araçlarıdır. Anahtar Kelimeler: Sezaryen doğum, planlanmış davranış teorisi, senaryo, İran
\end{abstract}

PRECIS: Reviewing of normal vaginal delivery scenarios based on theory of planned behavior, in pregnant women could decrease relative risk of choosing CS compared with the control by 0.15 .

Address for Correspondence/Yazıșma Adresi: Mohammad Mirrezaie, MD,

Shahroud University of Medical Sciences, Center for Health-Related Social and Behavioral Sciences Research, Shahroud, Iran

Phone: +989123047255 E-mail: mirrezaie@shmu.ac.ir ORCID ID: orcid.org/0000-0001-5352-4244

Received/Geliș Tarihi: 05.10.2018 Accepted/Kabul Tarihi: 06.01.2019

${ }^{\oplus}$ Copyright 2019 by Turkish Society of Obstetrics and Gynecology

Turkish Journal of Obstetrics and Gynecology published by Galenos Publishing House 


\section{Introduction}

According to the World Health Organization (WHO), the ideal rate of cesarean section (CS) surgeries among healthy nulliparous women is $10 \%$ to $15 \%$, but in many countries, it has continued to increase during the past three decades ${ }^{(1)}$. For example, CS rates in Latin America and the Caribbean, Europe, Asia, and Iran are 40.5\%, 25\%, 19.2\%, and 48\%, respectively ${ }^{(2,3)}$.

Among pregnant Iranian women, $70 \%$ of those who opt for CS delivery do so for reasons other than medical needs, including personal request, spouse's priorities, and sometimes, inducement by physicians, so the mother's decision is one of the main factors for the increase in CS deliveries ${ }^{(4)}$. Evidence suggests that training women to develop skills of overcoming a fear of normal vaginal delivery (NVD), reducing labor pain ${ }^{(5)}$, raising women's awareness regarding the advantages and disadvantages of a given delivery method ${ }^{(6,7)}$, and engaging them in the process of decision-making on delivery method ${ }^{(8)}$ are effective ways of reducing CS-favoring decisions. The effectiveness of health education programs is substantially related to applied educational theories and models ${ }^{(9)}$. One of the most important theories for predicting and understanding behavior is the theory of planned behavior (TPB), whose effectiveness has been confirmed in experimental studies ${ }^{(9,10)}$. The theory maintains that a particular behavior can be predicted on the basis of behavioral intention. Based on the theory of planned behavior, if a person assumes a behavior to be reflective of good conduct (positive attitude), they believe that others will regard it as valuable behavior (positive mental norm); accordingly, they will also intend to perform it. ${ }^{(11)}$ Childbirth stories or scenarios help women to select the best delivery mode because these narratives help them identify unknown aspects of delivery, reduce fear, and increase a sense of control ${ }^{(12)}$. Various studies have confirmed the importance of scenarios in learning ${ }^{(13,14)}$. Peer experiences, such as narrating childbirth stories, influence the choice of delivery method ${ }^{(15)}$ because negative stories about NVD motivated pregnant women to select $\mathrm{CS}^{(16,17)}$. In a study conducted by Blainey and Slade (2015), the writing and sharing of childbirth stories by women who experienced traumatic delivery exerted positive mental health effects on the women ${ }^{(18)}$.

To address this capability of scenario, the present study evaluated the effects of reviewing written childbirth scenarios on the decision of nulliparous women regarding delivery method (i.e., NVD vs. CS). The examination was based on TPB.

\section{Materials and Methods}

\section{Study design}

The study was designed as a parallel randomized controlled trial with three arms conducted in the prenatal clinic of the gynecology department of a governmental hospital, Shohada
Women's Hospital of Behshahr, a northern Iranian city located in the Mazandaran province. The study received an ethics code (Ir.shmu.rec.1394.32) from Shahroud University of Medical Sciences, and was approved by Mazandaran University of MedicalSciences. Thestudy was registered in the Iranian Center for Registration of Clinical Trials (IRCT2015052020706N2) and the study protocol is available in http://fa.search.irct.ir/ search?query=IRCT2015052020706N2.

\section{Participants}

All pregnant women who visited the clinic from May through December 2015 were considered for the study. To recruit suitable participants, we approached eligible women during their first visit to the clinic. The inclusion criteria were primigravid pregnant women, single-fetus pregnancies, gestational age of 28 to 32 weeks, maternal age of 18 to 35 years, no history of frequent abortion, and no contraindication for normal childbirth. The exclusion criteria were unwillingness to participate in training courses, absence from one of the training sessions, and obstetric or medical contraindications to vaginal birth and/or trial of vaginal birth (e.g., placenta previa). All participants gave written informed consent.

\section{Randomization and masking}

Using computer-generated random blocks of six, we randomly assigned 233 eligible participants to three study groups with an allocation ratio of 1:1, namely, two intervention groups [TPB-based education (TPB group) and TPB-based education plus additional support via written childbirth scenarios (scenario group)], each consisting of 74 participants, and a control group, who received standard care (75 participants) (Figure 1). The randomization was supervised by statisticians who were not involved in the enrolment or follow-up of participants. The clinic's employees could not be subjected to masking from the group assignments because of the nature of the interventions.

\section{Procedures}

For the implementation of TPB-based education and TPBbased education plus additional support with written childbirth scenarios, we trained the healthcare staff of the prenatal and maternity departments of the intervention facility by using a WHO course ${ }^{(18)}$. Considering the lack of a standard questionnaire in this field, a study-specific instrument was developed on the basis of TPB resources and textbooks and the results of previous studies ${ }^{(19-21)}$. The questionnaire comprised 80 questions distributed across two sections. The first section, whose composition was based on the questions used by Hildingsson et al., ${ }^{(20)}$ revolves around awareness related to childbirth, socio-demographic characteristics, and obstetric background. The specific items falling under this section are those related to demographics (age, occupation, and education of the expectant mother 
and her spouse, place of residence, and economic status), midwifery issues (e.g., date of last menstrual period, probable date of delivery, gestational age, gravity, parity, number of embryos in the current pregnancy), awareness (10 items on awareness about normal childbirth and CS, pros and cons of different delivery methods for the mother and the fetus, and scientific indications of CS), and results evaluation (10 items). To assess the economic situation, the questionnaire also presents questions regarding household assets. Using principal components analysis and considering three layers, we classified economic status into high, medium, and low levels. The second section of the questionnaire consists of the end-structures of TPB, including attitude toward an act (16 items), subjective norms ( 5 items), perceived behavioral control (3 items), behavioral intention (2 items), and behavioral performance (1 item).

Pregnant women belonging to the intervention groups were scheduled for educational TPB-based interventions in groups of 10 to 12 people; however, the control group was administered only routine services by the healthcare staff. The educational interventions were conducted at three 60-minute weekly sessions. The structures of the sessions are presented

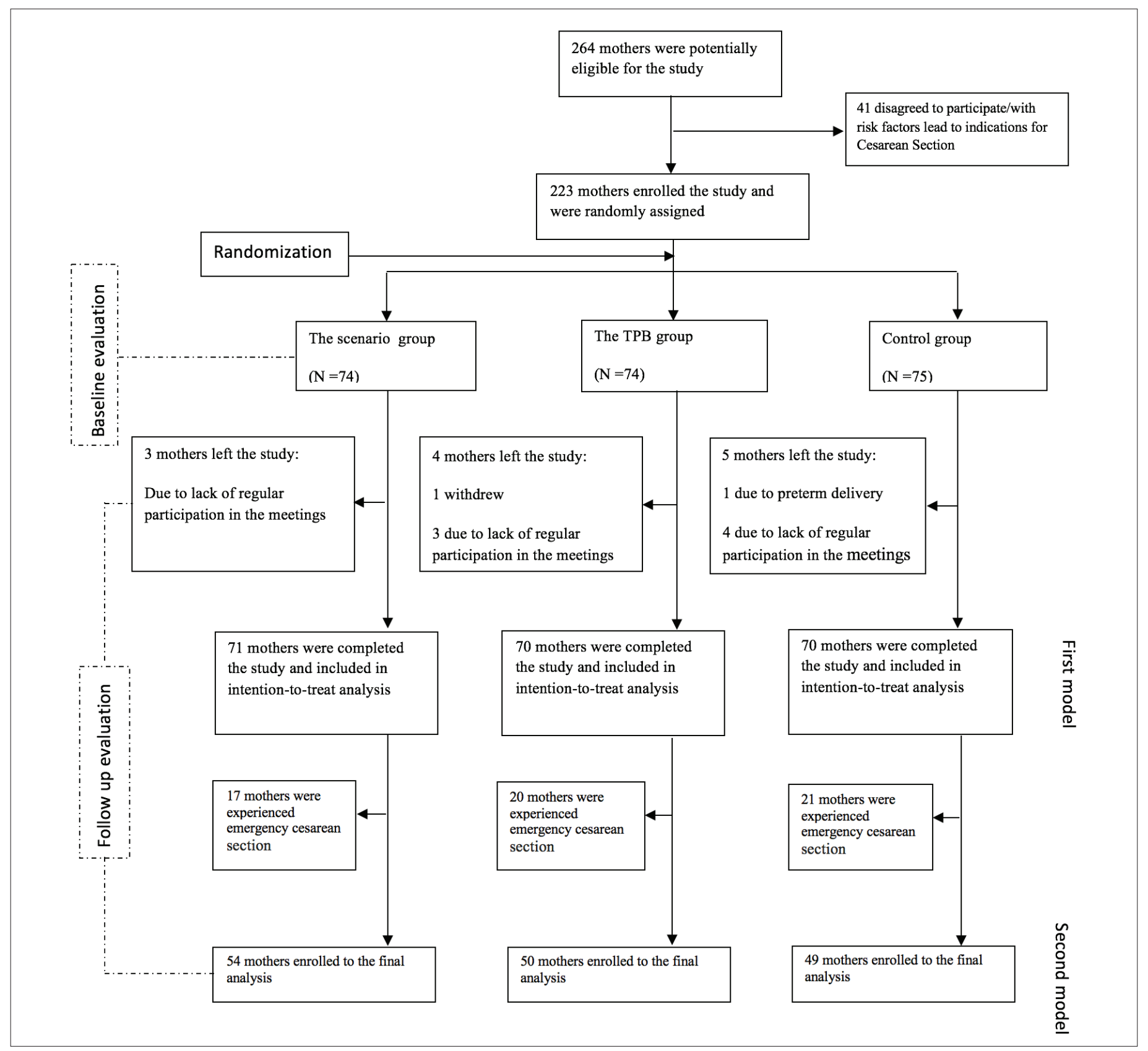

Figure 1. Trial profile

TPB: Theory of planned behavior 
in Table 1 (see appendix 1 for more details regarding the training). Both the interventional groups and the control group received a training manual on the advantages of NVD and the non-pharmacologic methods of pain relief.

The written scenarios, which were composed on the basis of actual situations, consisted of six positive stories about the physiological childbirth process with non-pharmacologic pain relief methods that were helpful to mothers and two negative stories about unscientific CS deliveries that were performed at the mothers' request (appendix 2). The scenario group was asked to read the scenarios before the next meeting and identify the points that they believed were useful, interesting, and functional.

At each subsequent session, the stories were reviewed with the participants to help them improve their understanding of difficult sentences, increase the attractiveness of the stories, and create a deep connection to the narratives. The practical strategies for story review included pausing, thinking, and retelling. Encouraging individuals to pause after reading part of a story, ponder over this part, and retell it to others helps them better learn about the story; it also allows them to determine how much of the story they can recall(22). After a review of each scenario, the participants were asked to express their feelings and impressions of each scenario.

The participants of the three groups were asked to complete a pre and post-test questionnaire at 37 weeks of pregnancy and one month after the completion of the educational interventions, respectively.

\section{Outcomes}

We assessed one primary outcome, that is, the proportion of mothers who intended to opt for NVD, within one month after the completion of the educational interventions. This decision was based on TPB's argument that intention is the main factor that determines behavior (see Introduction). We also assessed a secondary outcome, that is, the prevalence of NVD selection among the mothers.

\section{Statistical Analysis}

Mean \pm SD (standard deviation) and frequency were reported as descriptive statistics. ANOVA was performed to compare the continuous outcomes of the groups. Chi-square and Fisher's exact tests were also performed for categorical variables. Log-binomial regression models were used to explore the relative risk (RR) of the decision to undergo a CS (first model) and the risk of CS delivery (second model) in the groups for which other covariates were adjusted. In the modeling, the control group was considered as a reference category. All the analyses were conducted in STATA version 12 , and the significance level was considered as 0.05 .

\section{Results}

As previously stated, we randomly assigned 223 participating mothers to three groups; 74,74 , and 75 women were assigned to the scenario (PTB + written scenarios), PTB (PTBbased education only), and control (routine care) groups, respectively. A total of 211 participants were included in the analysis. The loss to follow-up rate was about $5 \%$. The mean age of the women was $24.9 \pm 4$ years. Some of them had diplomas (34.6\%), and many were housewives (88.6\%). The baseline characteristics of the women according to groups are shown in Table 2.

The primary decision for delivery chosen by the study groups at the beginning of the study showed no significant differences (Table 2). However, the frequencies of NVD selection in the scenario, TPB, and control groups as a primary outcome were $73.2 \%, 58.5 \%$, and $45.7 \%$, respectively ( $\mathrm{p}=0.004$ ).

In the first log-binomial regression model, the regression was run on the decision for CS as an outcome variable in the presence of other covariates. The results showed that the RR of the decision to undergo CS in the scenario and TPB groups in comparison with the control group were both 0.87 and statistically significant ( $\mathrm{p}=0.018$ and $\mathrm{p}=0.013$, respectively).

Table 1 . Intervention by study groups

\begin{tabular}{llll}
$\begin{array}{l}\text { Training } \\
\text { session }\end{array}$ & $\begin{array}{l}\text { Control } \\
\text { group }\end{array}$ & TPB group & What interventions were delivered and for whom \\
\hline First session & None & $\begin{array}{l}\text { Brainstorming about advantages of NVD } \\
\text { Talking about positive outcomes }\end{array}$ & $\begin{array}{l}\text { TPB plus written scenarios group } \\
\text { Talking about positive outcomes }\end{array}$ \\
\hline Second session & None & $\begin{array}{l}\text { Role playing } \\
\text { Group discussion }\end{array}$ & Reviewing written scenarios (1-3) \\
\hline Final session & None & $\begin{array}{l}\text { Non-pharmacologic methods of labor pain } \\
\text { relief } \\
\text { Talking about facilitating factors } \\
\text { Small steps of behavioral intention }\end{array}$ & $\begin{array}{l}\text { Role playing } \\
\text { Group discussion }\end{array}$ \\
& & $\begin{array}{l}\text { Reviewing written scenarios (4-6) } \\
\text { Talking about facilitating factors } \\
\text { Small steps of behavioral intention }\end{array}$ \\
\hline TPB: Theory of planned behavior, NVD: Normal vaginal delivery & Reviewing written scenarios (7-8)
\end{tabular}


Table 2. Baseline characteristics of participants

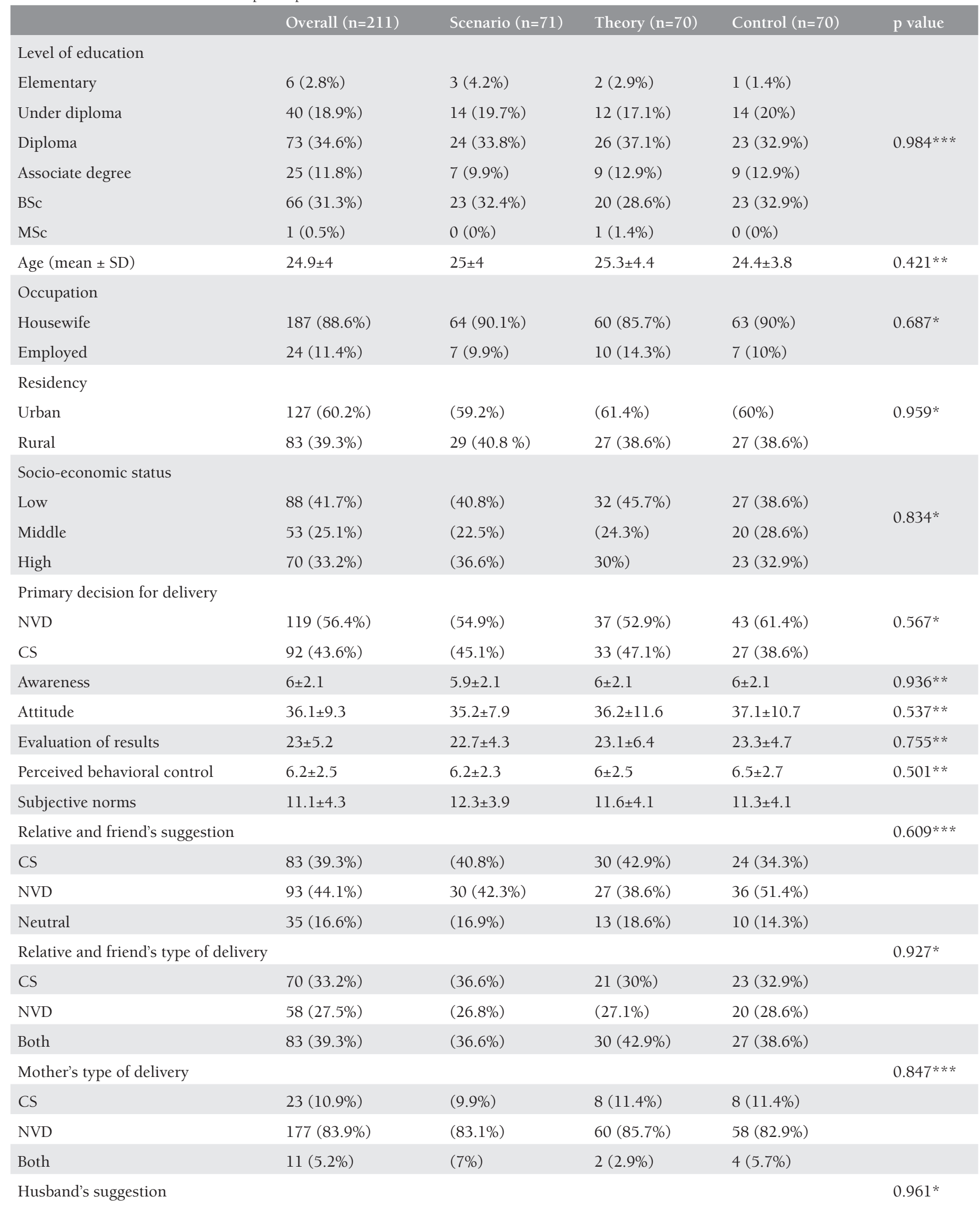




\begin{tabular}{|c|c|c|c|c|c|}
\hline NVD & $85(40.3 \%)$ & $28(39.4 \%)$ & $(38.6 \%)$ & $30(42.9 \%)$ & \\
\hline Neutral & $60(28.4 \%)$ & $(26.8 \%)$ & (30\%) & $20(28.6 \%)$ & \\
\hline Mother's suggestion & & & & & $0.851^{*}$ \\
\hline NVD & $118(55.9 \%)$ & $(54.9 \%)$ & 37 (52.9\%) & $42(60 \%)$ & \\
\hline Neutral & $32(15.2 \%)$ & (14.1\%) & $13(18.6 \%)$ & 9 (12.9\%) & \\
\hline
\end{tabular}

*Chi-square test, **ANOVA, ***Fisher exact test

SD: Standard deviation, NVD: Normal vaginal delivery, CS: Cesarean section

Table 3. Log-binomial regression on CS decision (first model) and CS delivery (second model)

Log-binomial regression models

First model $(\mathrm{n}=211)$

Relative risk
Second model ( $\mathrm{n}=153)$ Relative risk $\quad 95 \% \mathrm{CI}$

$\mathrm{p}$ value

\section{Group}

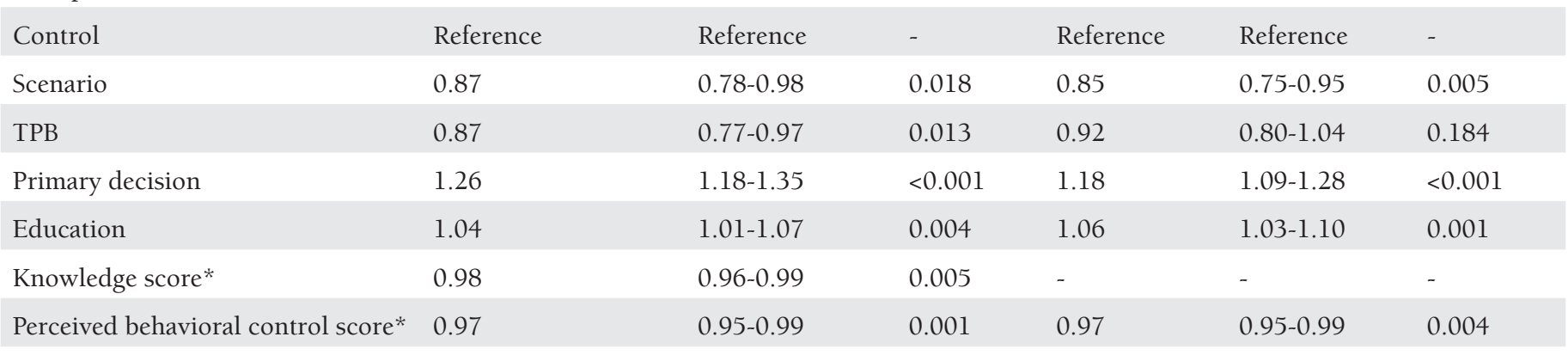

*Difference between pre and post test, TPB: Theory of planned behavior, cs: Cesarean section

The findings also indicated that the primary decision to undergo CS $(\mathrm{RR}=1.26, \mathrm{p}<0.001)$ and a high level of education ( $R R=1.04, p=0.004)$ were associated with an increased $R R$ of the decision to undergo CS. An increase in perceived behavioral control and in awareness scores decreased the RR of the decision for CS (Table 3).

The number of CS deliveries performed in this study was 86 (40.76\%), among which 58 (67.44\%) and 28 (32.56\%) were performed for emergency and elective reasons, respectively. In the second model, women for whom obligatory CS delivery was prescribed were excluded, leaving us with a sample of 153 participants. The log-binomial regression with CS as an outcome variable in the presence of covariates was repeated. The findings showed that the RR of CS in the scenario group was 0.85 , which was statistically significant $(\mathrm{p}=0.005)$. No statistical difference was found between the TPB and control groups. The primary decision to opt for CS $(R R=1.18, p<0.001)$ and higher level of education $(R R=1.06$, $\mathrm{p}=0.001$ ) increased the RR of CS. Increased in the difference of perceived behavioral control score between pre and posttest was decreased RR of CS decision $(\mathrm{RR}=0.97 . \mathrm{p}=0.004)$ (Table 3).

\section{Discussion}

Our results showed that using positive stories about childbirth in the TPB model is an effective strategy for enhancing the predilection of pregnant women to select NVD as a delivery mode. In both intervention groups, TPB strongly predicted behavioral intention. The interventions were also associated with a significantly reduced prevalence of CS decision in the intervention groups. Although the written scenarios exerted the greatest effects on the behavioral constructs, no significant difference in behavioral performance was found between the TPB and control groups.

In a study conducted in northern Iran, Besharati et al. ${ }^{(19)}$ found that intervention based on TPB effectively reduced the incidence of elective CS and increased the selection of NVD. However, only half of the participants of intervention group who exhibited an intention to select NVD actually chose this type of delivery.

In the current research, after the removal of emergency CS cases, the log-binomial regression showed that the RR of CS decision significantly decreased in the scenario group compared with the risk observed in the control group $(p=0.005)$. The RR of CS decision in this group relative to 
the control and TPB groups decreased by 0.15 and 0.07 , respectively. In a study performed by Regan et al., ${ }^{(23)} 71.2 \%$ of the women stated that the most important and valuable resource that helped them to select a method of delivery was stories of childbirth by other women.

In our study, stories as powerful educational tools had a significant effect on the behavioral tendency of the nulliparous women to reduce CS decisions. This effect seems to have originated from the characteristics of the stories, which are believable and memorable. They are believable because they originated from human and pseudo-human experiences that people are inclined to perceive as authentic scientific sources. They are memorable because they inspire involvement in the characters' intentions and performance ${ }^{(24)}$. Bruner (1986) argued that stories developed an awareness and performance outlook in humans and that these two were part of human intentions; an audience becomes involved with a story at both levels, and through this involvement, enters the minds of characters and achieves an improved understanding of story meanings ${ }^{(25)}$.

Hearing negative stories about normal childbirth was one of the factors that triggered the decision to opt for CS among women in a study conducted in northern Iran ${ }^{(16)}$. In a study performed in North Carolina, Romero et al. ${ }^{(26)}$ discovered that the formation of the initial fear of normal childbirth in some women was due to the fact that they heard unfavorable stories from friends and acquaintances. On the other hand, confidence in one's ability to have NVD and the belief that vaginal childbirth is a normal method of giving birth were among the principal drivers of NVD decision.

Our study showed that the intention to opt for vaginal delivery in the two intervention groups significantly differed from that in the control group. After the educational interventions, the changes in women's awareness and perceived behavioral control were associated with a reduced risk of CS decision. Additionally, a direct correlation was found between the initial decision of women to undergo CS and their levels of education and the risk of CS decision. Rahman et al. ${ }^{(27)}$ (2014) and Rajabi et al. ${ }^{(28)}$ (2015) in Iran and in Malaysia found that high levels of education among mothers were associated with an increase in CS delivery.

In the scenario group, projection with the heroines in the stories helped the pregnant women recognize their latent capacities and eliminate their unknown fears and concerns. Lindesmith and McWeeny ${ }^{(29)}$ found that a story established a connection between women and their shared backgrounds and that sharing stories regarding childbirth, as a seminal experience, should officially be taken into consideration in childbirth training programs. In a review, Webb et al. ${ }^{(30)}$ (2010) found that interventions based on TPB had a significant effect on behavior. The authors emphasized that the closer the integration of intervention with behavioral change techniques, the better the performance effects derived. In the NVD scenarios, the heroine-like roles of the characters and confidence in women's power to manage labor pains improved the perceived behavioral control capabilities of the readers. For these women, therefore, normal childbirth was viewed as achievable and realistic. A study showed that nulliparous women regarded childbirth stories as a way of facilitating the selection of normal childbirth. The study also indicated that creating new positive real stories or narratives effectively reduced the choice of CS delivery and increased the motivation to select normal childbirth ${ }^{(31)}$. In the current study, the infrastructures of the stories helped instill the truth in the mindsets of the women and improve the decisionmaking process underlying childbirth.

To the best of our knowledge, although childbirth stories are often used in qualitative research, in the present study we used them in a clinical trial to determine their efficacy. A limitation worth mentioning is that the effects of traumatic delivery scenarios on the choice of delivery method were not examined, also the study involved nulliparous women only. This present study shows that a combination of childbirth scenarios and training based on TPB could be used to reduce the incidence of unnecessary CS deliveries.

\section{Acknowledgments}

We would like to thank the Shahroud University of Medical Sciences for supporting the study (grant number: 93106) and Mazandaran University of Medical Sciences who took part in this study. We thank the study mothers for their participation and time; personnel of the participating clinic for their time and efforts.

Ethics

Ethics Committee Approval: The study received an ethics code (Ir.shmu.rec.1394.32) from Shahroud University of Medical Sciences, and was approved by Mazandaran University of MedicalSciences. Thestudy was registered in the Iranian Center for Registration of Clinical Trials (IRCT2015052020706N2) and the study protocol is available in http://fa.search.irct.ir/ search?query=IRCT2015052020706N2.

Informed Consent: All participants gave written informed consent.

Peer-review: External and internal peer-reviewed.

\section{Authorship Contributions}

Surgical and Medical Practices: GYN ward staff. Concept: S.M.M., M.R., Design: S.M.M., M.R., M.F., Data Collection or Processing: M.R., R.Z.H., E.F., Analysis or Interpretation: S.M.M., M.R., M.F., Literature Search: M.R., R.Z.H., E.F., Writing: S.M.M., M.R., M.F., R.Z.H., E.F.

Conflict of interest: The authors have declared no conflicts of interest.

Financial Disclosure: This study was supported by grant No 940167 from Shahroud University of Medical Sciences and granted approval by Mazandaran University of Medical Sciences. 


\section{References}

1. Gibbons L, Belizán JM, Lauer JA, Betrán AP, Merialdi M, Althabe F. The global numbers and costs of additionally needed and unnecessary caesarean sections performed per year: overuse as a barrier to universal coverage. World health report 2010;30:1-31.

2. Betrán AP, Ye J, Moller A-B, Zhang J, Gülmezoglu AM, Torloni MR. The Increasing Trend in Caesarean Section Rates: Global, Regional and National Estimates: 1990-2014. PloS one 2016;11:e0148343.

3. Azami-Aghdash S, Ghojazadeh M, Dehdilani N, Mohammadi M, Asl Amin Abad R. Prevalence and Causes of Cesarean Section in Iran: Systematic Review and Meta-Analysis. Iran J Public Health 2014:43:545-55. PubMed PMID: 26060756. Pubmed Central PMCID: PMC4449402. Epub 2015/06/11. eng.

4. Eslami S, Aslani A, Tara F, Ghalichi L, Erfanian F, Abu-Hanna A. The impact of a computerized decision aid on empowering pregnant women for choosing vaginal versus cesarean section delivery: study protocol for a randomized controlled trial. Trials 2015;03;16:549. PubMed PMID: 26634922. Pubmed Central PMCID: PMC4669643. Epub 2015/12/05. eng.

5. Edmonds JK, Cwiertniewicz T, Stoll K. Childbirth Education Prior to Pregnancy? Survey Findings of Childbirth Preferences and Attitudes Among Young Women. J Perinat Educ 2015;24:93-101. PubMed PMID: 26957892. Pubmed Central PMCID: PMC4744342. Epub 2015/01/01. eng.

6. Boz I, Teskereci G, Akman G. How did you choose a mode of birth?Experiences of nulliparous women from Turkey. Women Birth 2016;29:359-67. PubMed PMID: 26846560. Epub 2016/02/06. eng.

7. Hauck YL, Stoll KH, Hall WA, Downie J. Association between childbirth attitudes and fear on birth preferences of a future geAnuesrtartaiolinan of parents. Women Birth 2016;29:511-517. doi: 10.1016/j.wombi.2016.05.001. Epub 2016 May 24. PubMed PMID: 27233945. Epub 2016/05/29. eng.

8. McCants BM, Greiner JR. Prebirth Education and Childbirth Decision Making. International Journal of Childbirth Education 2016;31.

9. Glanz K, Rimer BK, Viswanath K. Health behavior and health education: theory, research, and practice: John Wiley \& Sons; 2008.

10. Sharma M. Theoretical foundations of health education and health promotion: Jones \& Bartlett Publishers; 2016.

11. Ajzen I. The theory of planned behaviour. Organizational Behaviour and Human Decision Processes, 50, 179-211. De Young 1991:50926.

12. Nichols FH, Humenick SS. Childbirth education: practice, research and theory: WB Saunders Company; 2000.

13. Bremner MN, Aduddell K, Bennett DN, VanGeest JB. The use of human patient simulators: best practices with novice nursing students. Nurse Educ 2006;31:170-4. PubMed PMID: 16855487. Epub 2006/07/21. eng.

14. Yackley LE. Storytelling: A key to adult learning: University of Delaware; 2007.

15. Kornelsen J, Hutton E, Munro S. Influences on decision making among primiparous women choosing elective caesarean section in the absence of medical indications: findings from a qualitative investigation. J Obstet Gynaecol Can 2010;32:962-9. PubMed PMID: 21176305. Epub 2010/12/24. eng.

16. SHirvani MA, Bagheri-Nesami M, Tayebi T. Exploration of women birth experiences role in decisiding the type of next delivery. J Urmia Nurs Midwifery Fac 2014;12:286-96.

17. Rahmati N. An exploratory study of women's experiences of fear about childbirth: University of British Columbia; 2014.

18. Organization WH. Care in normal birth: a practical guide. 1996.

19. Besharati F, Hazavehei S, Moeini B, Moghimbeigi A. Effect of educational interventions based on theory of planned behavior (TPB) in selecting delivery mode among pregnant women referred to rasht health centers. ZUMSJ 2011;19:94-106.

20. Hildingsson I, Radestad I, Rubertsson C, Waldenstrom U. Few women wish to be delivered by caesarean section. BJOG 2002;109:618-

23. PubMed PMID: 12118637. Epub 2002/07/18. eng.

21. Fathian Z, Sharifirad GR, Hasanzadeh A. Study of the effects of Behavioral Intention Model education on reducing the cesarean rate among pregnant women of Khomeiny-Shahr, Isfahan, in 2006. 2007.

22. Robb L. Reading strategies that work: Teaching your students to become better readers: Scholastic Inc.; 1996.

23. Regan M, McElroy KG, Moore K. Choice? Factors That Influence Women's Decision Making for Childbirth. J Perinat Educ 2013;22:171-80. PubMed PMID: 24868129. Pubmed Central PMCID: PMC4010239. Epub 2014/05/29. eng.

24. Taylor K, Marienau C, Fiddler M. Developing Adult Learners: Strategies for Teachers and Trainers. The Jossey-Bass Higher andAdult Education Series: ERIC; 2000.

25. Minds A. Possible Worlds Cambridge. MA Harvard UP. 1986.

26. Romero ST, Coulson CC, Galvin SL. Cesarean delivery on maternal request: a western North Carolina perspective. Maternal and child health journal. 2012;16:725-34. PubMed PMID: 21400201. Epub 2011/03/15. eng.

27. Rahman M, Shariff AA, Shafie A, Saaid R, Tahir RM. Determinants of Caesarean Risk Factor in Northern Region of Bangladesh: A Multivariate Analysis. Iran J Public Health 2014;43:16-27.

28. Rajabi A, Maharlouei N, Rezaianzadeh A, Rajaeefard A, Gholami A. Risk factors for C-section delivery and population attributable risk for C-section risk factors in Southwest of Iran: a prospective cohort study. Med J Islam Repub Iran. 2015;16;29:294. eCollection 2015.

29. Lindesmith KA, McWeeny M. The power of storytelling. J Contin Educ Nurs 1994;25:186-7.PubMed PMID: 8046058. Epub 1994/07/01. eng.

30. Webb TL, Joseph J, Yardley L, Michie S. Using the internet to promote health behavior change: a systematic review and meta-analysis of the impact of theoretical basis, use of behavior change techniques, and mode of delivery on efficacy. Journal of medical Internet research. 2010:17;12:e4. PubMed PMID: 20164043. Pubmed Central PMCID: PMC2836773. Epub 2010/02/19. eng.

31. Happel-Parkins A, Azim KA. At pains to consent: A narrative inquiry into women's attempts of natural childbirth. Women and birth: journal of the Australian College of Midwives. 2016:29;310-20. PubMed PMID: 26639037. Epub 2015/12/08. eng. 